\section{Authors' response-Approach to evaluating the reliability and validity of conjunctival ultraviolet autofluorescence measurement}

We thank Sabour and Ghassemi for their interest in our recent publication. ${ }^{1}$ Clearly the assessment of validity and reliability is important when developing a novel tool to objectively measure ocular ultraviolet radiation exposure.

The concordance correlation coefficient (CCC) was used in our study because it provides a robust and valid approach for the assessment of reliability between measures of continuous variables. ${ }^{2}$ Several other measures of reliability of continuous variables are available, including the intraclass correlation coefficient (ICC); however, these measures do not address both precision and accuracy as does the CCC. ${ }^{3}$ Under certain conditions, the CCC produces results that are almost identical to that of the ICC. ${ }^{4}$ For example, in our study the interobserver CCC for 'total' ultraviolet autofluorescence (UVAF) was 0.924, while the calculated ICC was 0.923. For intraobserver reliability of 'total' UVAF, the CCC was 0.988 and ICC 0.989 , respectively.

$\kappa$ was used to assess reliability of categorised UVAF measures. Clearly the results from such analysis will be largely determined by the choice of category limits. Hence, we presented data for two different definitions (groups of either $5 \mathrm{~mm}^{2}$ or $10 \mathrm{~mm}^{2}$ ), and these category limits were selected to potentially reflect clinically meaningful differences. Moreover, we used unweighted $\kappa$ because deciding on appropriate weights is subjective. Nonetheless, our interpretation of the $\kappa$ statistic is in accordance with published guidelines, ${ }^{5}$ although the choice of cut-offs in defining 'good agreement' is inevitably arbitrary, and other interpretations exist.

It is appreciated that the interpretation of $\kappa$ should incorporate sound clinical judgement. However, it must be noted that the clinical correlations of this recently developed metric of ocular sun exposure has not been well studied in the clinical setting. We also acknowledge that one cannot reliably compare $\kappa$ values between different studies, as $\kappa$ values are sensitive to the prevalence of different categories, and to bias.

Finally, in response to the statement 'UVAF correlates strongly with the authors' survey-based assessment of time spent outdoors,' it is important to note that this correlation refers to a measure of validity, and not reliability. Nowhere in our manuscript did we report or suggest that this correlation was a measure of reliability.

\section{Justin C Sherwin, ${ }^{1,2}$ Alex W Hewitt, ${ }^{1}$ Charlotte M McKnight, ${ }^{3}$ Lyn R Griffiths, ${ }^{4}$ Minas T Coroneo, ${ }^{5}$ David A Mackey ${ }^{1,3,6}$}

${ }^{1}$ Department of Ophthalmology, Centre for Eye Research Australia, Royal Victorian Eye and Ear Hospital, University of Melbourne, Melbourne, Victoria, Australia; ${ }^{2}$ Department of Public Health and Primary Care, Institute of Public Health, University of Cambridge, Cambridge, UK; ${ }^{3}$ Centre for Ophthalmology and Visual Science, University of Western Australia, Lions Eye Institute, Perth, Australia; ${ }^{4}$ Genomics Research Centre, Griffith Health Institute, Griffith University, Southport, Queensland, Australia; ${ }^{5}$ Department of Ophthalmology, University of New South Wales, Sydney, New South Wales, Australia; ${ }^{6}$ Department of Ophthalmology, Royal Hobart Hospital, University of Tasmania, Hobart, Tasmania, Australia

Correspondence to Professor David A Mackey, Lions Eye Institute, Centre for Ophthalmology and Visual Science, University of Western Australia, 2 Verdun St, Nedlands, 6009 Western Australia, Australia; d.mackey@utas.edu.au

Contributors JS wrote the original article. All of the other authors and JS contributed to the conception of the article, critically revising for important intellectual content, and final approval of the article.

\section{Competing interests None.}

Provenance and peer review Commissioned; internally peer reviewed.

Published Online First 27 June 2012

Br J Ophthalmol 2012;96:1271.

doi:10.1136/bjophthalmol-2012-302135

\section{REFERENCES}

1. Sherwin JC, McKnight CM, Hewitt AW, et al. Reliability and validity of conjunctival ultraviolet autofluorescence measurement. $\mathrm{Br} J$ Ophthalmol 2012; $96: 801-5$

2. Lin LI. A note on the concordance correlation coefficient. Biometrics 2000;56:324-5.

3. Crawford SB, Kosinski AS, Lin HM, et al. Computer programs for the concordance correlation coefficient. Comput Methods Programs Biomed 2007;88:62-74.

4. Nickerson CA. A note on "a concordance correlation coefficient to evaluate reproducibility". Biometrics 1997;53:1503-7.

5. Altman D. Practical Statistics for Medical Research. London, England: Chapman and Hall, 1991. 


\section{BJO}

\section{Authors' response--Approach to evaluating the reliability and validity of conjunctival ultraviolet autofluorescence measurement}

Justin C Sherwin, Alex W Hewitt, Charlotte M McKnight, et al.

Br J Ophthalmol 2012 96: 1271 originally published online June 27, 2012

doi: 10.1136/bjophthalmol-2012-302135

Updated information and services can be found at:

http://bjo.bmj.com/content/96/9/1271.2.full.html

\section{These include:}

References This article cites 4 articles, 1 of which can be accessed free at: http://bjo.bmj.com/content/96/9/1271.2.full.html\#ref-list-1

Email alerting

Receive free email alerts when new articles cite this article. Sign up in service the box at the top right corner of the online article.

Notes

To request permissions go to:

http://group.bmj.com/group/rights-licensing/permissions

To order reprints go to:

http://journals.bmj.com/cgi/reprintform

To subscribe to BMJ go to:

http://group.bmj.com/subscribe/ 